\title{
Amino acid fluxes to and from seawater in axenic veliger larvae of a bivalve (Crassostrea gigas)
}

\author{
Donal T. Manahan
}

Department of Biological Sciences, University of Southern California, Los Angeles, California 90089-0371, USA

\begin{abstract}
Rates of uptake of dissolved amino acids were determined for axenic veliger larvae of the bivalve Crassostrea gigas ( $70 \mu \mathrm{m}$ shell length). Analyses of net fluxes from seawater of amino acids by high-performance liquid chromatography showed a net uptake of all acidic, basic, and neutral amino acids tested. From a substrate concentration of $100 \mathrm{nM}$ each, valine had the highest rate of uptake at 70 fmol larva ${ }^{-1} h^{-1}$, and arginine the lowest at $4 \mathrm{fmol}_{\text {larva }}{ }^{-1} \mathrm{~h}^{-1}$ The influx of alanine, arginine, glutamic acid and leucine (measured radiochemically) reflected the net flux (measured by chromatography). However, there was a net efflux of taurine $\left(0.58 \mathrm{pmol}\right.$ larva $\left.{ }^{-1} \mathrm{~h}^{-1}\right)$ even though isotope experiments revealed an influx of $0.32 \mathrm{pmol}$ larva ${ }^{-1} \mathrm{~h}^{-1}$ Efflux of taurine was aiso observed for nonaxenic veligers. Axenic veligers had a $K_{t}$ (substrate concentration at half $\mathrm{J}_{\max }$ ) of $11.4 \mu \mathrm{M}$ and a $\mathrm{J}_{\text {max }}$ (maximum transport capacity) of $4.6 \mathrm{pmol}$ larva ${ }^{-1} \mathrm{~h}^{-1}$ for alanine; for leucine, the corresponding values were $7.1 \mu M$ and 2.2 pmol larva ${ }^{-1} \mathrm{~h}^{-1}$ At substrate concentrations near the $\mathrm{K}_{\mathrm{t}}$ values (on the order of $10 \mu \mathrm{M}$ ), C. gigas larvae could account for $100 \%$ of their oxidative needs by the uptake of amino acids from seawater In most marine environments, such high concentrations are limited to seawater near the sediment. Thus, the overall contribution of dissolved amino acids will depend on the substrate concentration encountered by the larvae in nature.
\end{abstract}

\section{INTRODUCTION}

The ability of marine invertebrates to take up dissolved organic material (DOM) directly from seawater has interested marine scientists for over a century (Thomson 1873, Pütter 1909, Krogh 1931, Jørgensen 1976, Stephens 1988). Uptake of DOM (mainly amino acids and sugars) has been found to occur in all of the soft-bodied marine invertebrates studied to date, representing 13 phyla (Stephens \& Schinske 1961, Southward \& Southward 1972, Ferguson 1982). However, there was uncertainty as to whether transport rates, as measured with radioactively-labeled substrates, were an accurate measurement of the rate of total substrate accumulation into the organism (Johannes et al. 1969). Although the net removal of dissolved amino acids from seawater had been observed (Wright \& Stephens 1978), it was only with the application of high-performance liquid chromatography (HPLC) to the study of amino acid uptake that unequivocal identifications and quantifications of the uptake rates for individual substrates were achieved (Manahan et al. 1982).

A second and more difficult problem to overcome, with respect to the interpretation of uptake studies with marine invertebrates, was the possibility that bacteria were responsible for part or all of the observed uptake rate (D'Agostino 1972, Sieburth 1975, Siebers 1979). The development of techniques to produce axenic suspensions of invertebrate larvae permitted experiments which could directly address this critical problem (Langdon 1983, Manahan et al. 1983a).

Previous studies of net fluxes examined under axenic conditions have all been carried out on echinoderm larvae (Manahan et al. 1983a, Davis \& Stephens 1984). However, several authors have reported that the ability to take up DOM is widespread in larval forms. Such studies have employed radio-labeled substrates and investigated the phenomenon with nonaxenic larvae (Bass et al. 1969, Reish \& Stephens 1969, Rice et al. 1980, Manahan 1983). Bivalve larvae appear anatomically adapted to take up DOM. Their largest organ, the velum, which is used for swimming and feeding, is also the major organ responsible for the uptake of dissolved amino acids in several bivalve species studied (Manahan \& Crisp 1983). For bivalve larvae this is analogous to the situation found in the adult bivalve, where the gill is the major site of uptake (Pequignat 1973). In a previous study, data were presented on the rates of 
uptake and metabolism of radiolabeled-amino acids into nonaxenic larvae of the bivalve Crassostrea gigas (Manahan 1983). In the present study, axenic C. gigas larvae were used in a series of experiments designed to (1) compare the uptake of specific amino acids both individually and from mixtures, and (2) determine the relationship between influx and net flux for several substrates, representating acidic, basic, neutral and beta-amino acids (taurine).

\section{MATERIALS AND METHODS}

Animals. Ripe adult oysters Crassostrea gigas were obtained from Whiskey Creek Oyster Farms in Oregon (USA). Prior to spawning, the oysters were held in natural seawater at $17^{\circ} \mathrm{C}$ for 1 to $2 \mathrm{~d}$ in the laboratory in California.

The procedures described by Langdon (1983) were used to obtain bacteria-free gametes. Briefly, the procedures used were as follows. All manipulations were carried out under a sterile transfer hood with laminarflow (Labconco). The eggs and sperm of Crassostrea gigas are free of bacterial contamination in the gonad. Hence, by removing gametes directly from the gonad with sterile Pasteur pipettes, and performing all volume-transfers with sterile techniques, axenic gametes can be obtained. Eggs and sperm were placed in $50 \mathrm{ml}$ of autoclaved seawater. Fertilization was achieved by transferring an aliquot of the sperm into the flask containing the eggs and mixing by gentle hand shaking. In this way axenic suspensions of fertilized eggs were produced.

All culturing was carried out in natural seawater at $20^{\circ} \mathrm{C}$. Seawater was first passed through a $0.2 \mu \mathrm{m}$ polycarbonate filter (Nuclepore) prior to being placed as 51 aliquots into $6 \mathrm{l}$ Erlenmeyer flasks. The flask and seawater were then autoclaved at $120^{\circ} \mathrm{C}$ for $60 \mathrm{~min}$. Approximately $30 \mathrm{~min}$ after insemination, the embryos were placed in the $6 \mathrm{l}$ Erlenmeyer flask. Under these axenic conditions, ca $80 \%$ of the cultured embryos developed into normal D-veligers.

Several independent assays were employed to check for bacterial contamination in the larval cultures. Samples $(1 \mathrm{ml})$ of the seawater containing eggs and sperm were placed in $3 \mathrm{ml}$ of sterile nutrient broth (Ruby et al. 1980). If the larval culture was contaminated, the broth became cloudy after 2 to $3 \mathrm{~d}$. Some of these nutrient broths that did not indicate the presence of bacteria after $1 \mathrm{wk}$ were further incubated at room temperature for up to $1 \mathrm{yr}$. If, at the end of this time, they still did not become cloudy, they were then tested for false-negative results by inoculating the broth with raw seawater known to contain bacteria. In all cases the broths inoculated with bacteria did test positive for the presence of bacteria, indicating that the broths did not yield false-negative results.

In addition to testing every culture with broth medium, samples of seawater and axenic larvae were examined by microscopy for the presence of bacteria. Samples were treated with DAPI (diamidinophenylindole) (Porter \& Feig 1980), which stains bacterial nucleic acids, thereby allowing individual bacteria to be seen with epifluorescent microscopy. All larval cultures that tested negative for the presence of bacteria, using broth media, also tested negative with epifluorescent microscopy. A third test for bacteria occurred routinely in which replicate flasks contained sibling larvae were allowed to stand for up to $6 \mathrm{wk}$ after fertilization. If axenic, larvae were still alive and swimming at the end of this period. Nonaxenic cultures, however, always collapsed after $48 \mathrm{~h}$. This empirical test proved useful because larvae were usually left for at least $7 \mathrm{~d}$ prior to being used for experiments.

Larvae were kept in the culture vessels at very high densities (ca 500 to $1000 \mathrm{ml}^{-1}$ ) in particle-free seawater and, under these conditions, no growth occurred. The larvae used in all the experiments described below were the first veliger stage to develop from the trochophore (new D-veligers), and had a shell length of $70 \mu \mathrm{m}$. Any veligers that were seen to have any abnormal morphology of the shell, or abnormal swimming behavior indicative of a malformed velum, were not used for experiments. For experiments, larvae from healthy cultures were siphoned through autoclaved silicon tubing onto sterile-autoclaved plastic sieves covered with $44 \mu \mathrm{m}$ mesh. The larvae were then washed with $5 \mathrm{l}$ of fresh, sterile-autoclaved, seawater. Known aliquots were enumerated, and the larve distributed to the experimental flasks to give a known number $\mathrm{ml}^{-1}$.

Chemicals. Amino acids were obtained in powder from Sigma Chemical Co. Radiochemicals were purchased from either New England Nuclear $\left({ }^{14} \mathrm{C}\right.$-alanine, 168 or $170 \mu \mathrm{Ci} \mathrm{mol}^{-1} ;{ }^{14} \mathrm{C}$-taurine, $112 \mu \mathrm{Ci} \mu \mathrm{mol}^{-1}$ ) or I.C.N. $\left({ }^{14} \mathrm{C}\right.$-arginine, $270 \mu \mathrm{Ci} \mu \mathrm{mol}^{-1} ;{ }^{14} \mathrm{C}$-glutamic acid, $245 \mu \mathrm{Ci} \mu \mathrm{mol}^{-1} ;{ }^{14} \mathrm{C}$-leucine, $310 \mu \mathrm{Ci} \mathrm{mmol}^{-1}$ ). Water used for analysis in high-performance liquid chromatography (HPLC) was deionized, batch-distilled, and treated with UV-oxidation in a Barnstead Organic Pure system. All other reagents used for chromatographic analysis and other procedures were HPLC grade.

Simultaneous determination of net fluxes for multiple substrates. Larvae at various densities (see figure legends) were exposed to a mixture of 16 amino acids, representing acidic, basic and neutral amino acids. High densities of larvae had to be used to obtain accurate measurements of the rates of substrate removal. Each amino acid was initially present at a 
concentration of $250 \mathrm{nM}$. Samples $(500 \mu \mathrm{l})$ of the medium were removed from the experimental culture vessels $(40$ or $50 \mathrm{ml})$ at various time intervals. These samples were immediately passed through a $0.2 \mu \mathrm{m}$ polycarbonate filter held in a Pop-Top $13 \mathrm{~mm}$ filter holder (Nuclepore). All filter holders had been washed prior to use in $10 \% \mathrm{HCl}$ and given a final rinse in $50 \%$ isopropyl alcohol in order to avoid problems with amino acid contamination. Filtered samples were frozen at $-20^{\circ} \mathrm{C}$ until analyzed.

Changes in the concentrations of each amino acid with time were determined by reverse-phase HPLC analysis. The techniques used were based on the $o$ phthaldialdehyde (OPA) derivatization of primary amines (Lindroth \& Mopper 1979) and the subsequent separation of the fluorescent derivatives on C-18 columns using the sodium acetate buffer system of Jones et al. (1981), with the $\mathrm{pH}$ modified to 6.8. All the analyses presented here were carried out with a C-18 column packed with $3 \mu \mathrm{m}$ beads. This decreased the analysis time from around $30 \mathrm{~min}$ (with $5 \mu \mathrm{m}$ beads) to 16 min. A step gradient was developed to optimize the separation of the amino acids used in the current studies; at 0 min, $0 \% \mathrm{~B}$; at $1.1 . \mathrm{min}, 25 \% \mathrm{~B}$; at $4.4 \mathrm{~min}$, $50 \% \mathrm{~B}$; at $8.8 \mathrm{~min}, 75 \% \mathrm{~B}$; and at time $13.2 \mathrm{~min}, 100 \%$ $B$. Separations of the derivatives were achieved with a Beckman (Model \# 334) dual pump HPLC system. The eluted fluorescent products were detected with a Beckman fluorescence detector (Model \# 157) fitted with OPA filters. Peaks were integrated with a Spectra Physics computing integrator. Individual amino acid peaks were identified by retention time, and peak areas of the unknowns were compared to the integrated areas of known amounts of amino acids. These procedures permitted identification of the individual amino acids in the mixture and the net change in concentration over time for each of the amino acids tested.

Comparison of influx and net flux rates. The relationship between the influx of a radioactively-labeled substrate and the net flux of that substrate was determined for a representative acidic (glutamic acid), basic (arginine) and 2 neutral amino acids (alanine and leucine). In each experiment, aliquots of ${ }^{14} \mathrm{C}$-labeled substrates were added to solutions of known amino acid concentrations. Samples of $500 \mu \mathrm{l}$ were removed from a $50 \mathrm{ml}$ flask and filtered as before; ca $300 \mu \mathrm{l}$ were used for HPLC analysis, and exactly $200 \mu \mathrm{l}$ of seawater was placed in a $6 \mathrm{ml}$ scintillation vial to which $200 \mu \mathrm{l}$ of $0.1 \mathrm{M} \mathrm{HCl}$ had been added. Any acidvolatile components (e.g. ${ }^{14} \mathrm{CO}_{2}$ ) would be released from the acidified seawater after $24 \mathrm{~h}$, at which time scintillation cocktail (Fisher, Bio-HP) was added. After remaining in the dark for at least $16 \mathrm{~h}$, radioactivity in each vial was determined with an LKB scintillation counter (Model 1211). The rate of influx $\left({ }^{14} \mathrm{C}\right)$ of an amino acid could then be compared to its rate of net flux (HPLC)

Transport kinetics of single substrates. A series of time course experiments was carried out to determine the kinetics of alanine and leucine transport by axenic larvae. Crassostrea gigas larvae were exposed, in parallel, to a range of substrate concentrations of both alanine and leucine. Sibling larvae were used for these kinetic experiments which had been produced from fertilizing a single female with sperm from a single male. At each substrate concentration, a 6 to $8 \mathrm{~min}$ experiment was run to determine the rate of transport Larvae were incubated in $10 \mathrm{ml}$ of sterile seawater containing $1 \mu \mathrm{Ci}$ of ${ }^{14} \mathrm{C}$-amino acid and cold carrier at the required concentration. At known intervals of approximately every minute, a $500 \mu \mathrm{l}$ sample was removed and placed on $500 \mu \mathrm{l}$ of silicone oil (Versilube F-50, General Electric Co.) in a $1.5 \mathrm{ml}$ centrifuge tube. The larvae were centrifuged at $12500 \times g$ (Beckman Model 'E') to remove them from the seawater. The supernatant and oil were removed and the conical end of the test tube, containing the pelleted larvae, was cut off and placed in $500 \mu \mathrm{l}$ of tissue solubilizer (Fisher Scientific). Larvae were digested overnight, scintillation fluid was added, and the radioactivity in each vial was determined. Quenching was determined using internal standards $\left({ }^{14} \mathrm{C}\right.$-toluene, New England Nuclear) and quench correction curves, allowing the conversion of radioactivity to DPM. The rate of amino acid transport was calculated from the slope of the regression line. Using only the slope of the line, and not the $y$ intercept, eliminates possible artifacts in the calculation of transport rates caused by any residual isotope (adsorbed label or seawater carried into the pellet). The radioactivity in each pellet was corrected for specific activity, and the rate was expressed as pmol larva ${ }^{-1} \mathrm{~h}^{-1}$ for each substrate concentration.

\section{RESULTS}

\section{Simultaneous determination of net fluxes for multiple substrates}

Reproductions of representative HPLC chromatograms used to calculate uptake rates are shown in Fig. 1. The amounts of each of the 16 different amino acids tested were found to decrease with time (100 min) when axenic Crassostrea gigas larvae were in the seawater. The presence of taurine at the start and end of the experiment is a result of its efflux from the larvae and not from an addition of a taurine stock solution, as is the case for the other 16 amino acids. The observed efflux of taurine will be considered in greater detail below Control experiments, where the same concen- 

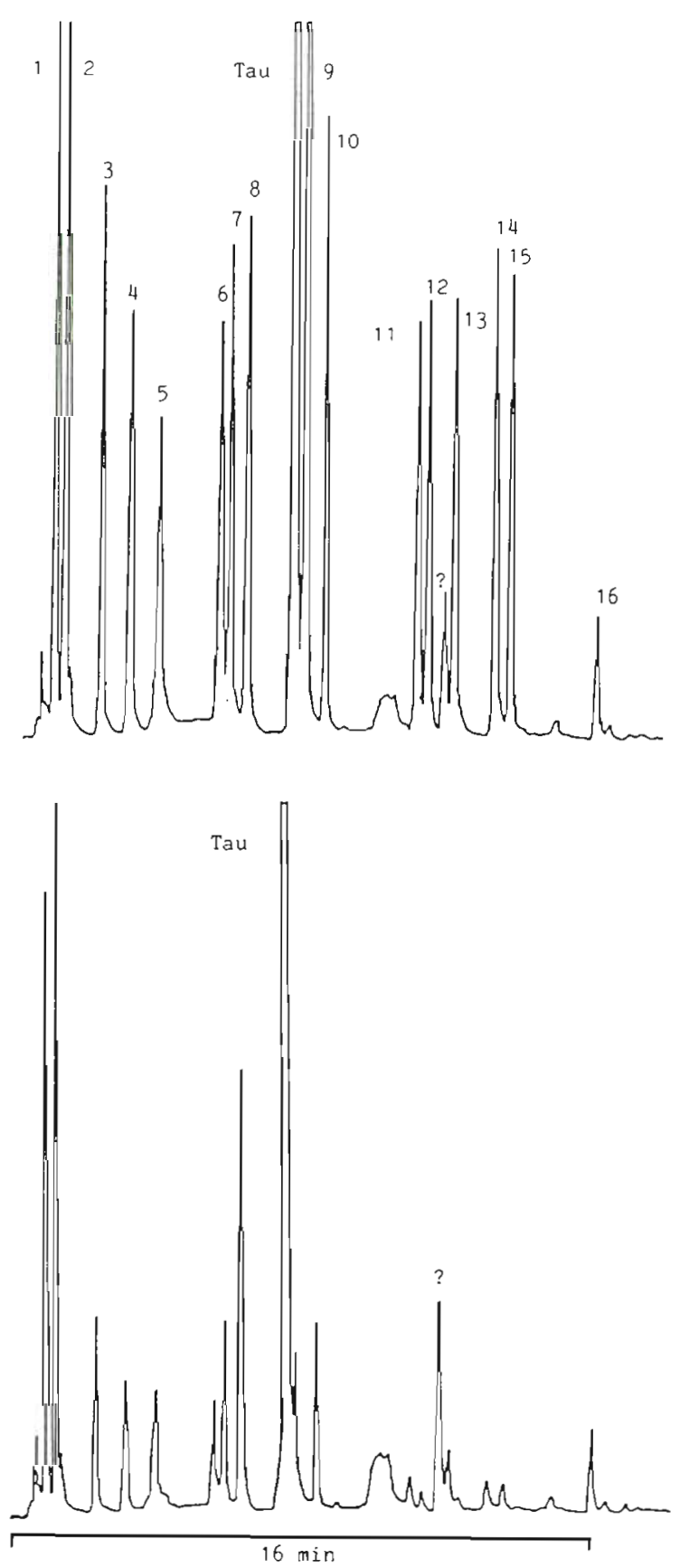

Fig. 1. Crassostrea gigas. HPLC chromatograms to illustrate the net uptake of dissolved amino acids from seawater by axenic lavae. Upper chromatogram shows the concentrations of amino acids at the start of the experiment (Time 0 , each amino present at $250 \mathrm{nM}$ except taurine). Lower chromatogram shows the changes in the amounts of individual amino acids in the medium afer $100 \mathrm{~min}$ exposure to larvae. (Volume of flask was $40 \mathrm{ml}$ 2586 larvae $\mathrm{ml}^{-1}$ ). 1 = aspartic acid (Asp); $2=$ glutamic acid $(\mathrm{Glu})_{i} 3=$ asparagine $(\mathrm{Asn}) ; 4=$ serine $($ Ser) $; 5=$ histidine (His); $6=$ glycine $($ Gly); $7=$ threonine (Thr); $8=$ arginine $(\mathrm{Arg}) ; 9=$ alanine $(\mathrm{Ala}) ; 10=$ tyrosine (Tyr); $11=$ methionine (Met); $12=$ valine $(\mathrm{Val}) ; 13=$ phenylalanine (Phe); $14=$ isoleucine (Ile); $15=$ leucine $(\text { Leu })_{i}$ $16=$ lysine $($ Lys $) ;$ Tau $=$ taurine $;=$ probably ammonium

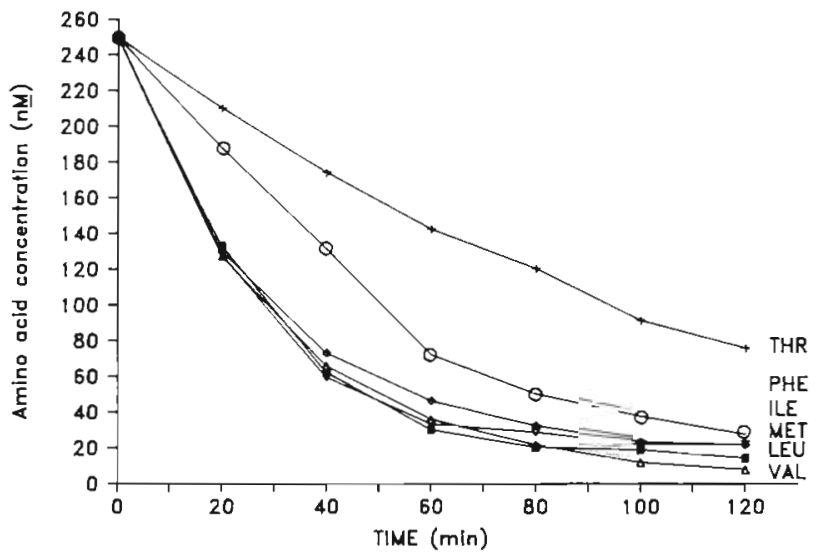

Fig. 2. Crassostrea gigas. Net removal with time by axenic larvae of the amino acids $\operatorname{Thr}(+)$, Phe(o), Ile( $(0)$, Met $(\nabla)$, Leu( $(\mathbf{\square}), \operatorname{Val}(\Delta) .\left(\right.$ Volume of flask $=40 \mathrm{ml} ; 2586$ larvae $\mathrm{ml}^{-1}$ )

trations of amino acids were incubated in replicate flasks containing no larvae, showed no detectable removal of amino acids from the medium (data not shown).

Fig. 2 gives a time course showing the simultaneous removal of 6 'essential' amino acids from seawater by axenic Crassostrea gigas larvae. Even though each amino acid was initially present at the same concentration of $250 \mathrm{nM}$, the data illustrate that the rates of net flux for individual amino acids from mixtures were not identical. Following a $120 \mathrm{~min}$ exposure, axenic C. gigas larvae removed valine to the limit of sensitivity for the HPLC analysis currently in use (5 $\mathrm{nM}$ ).

Because the substrate concentrations used in each experiment were less than the $K_{t}$ value for amino acid transport (see below), the rate of influx for each amino acid was calculated using first-order depletion constants (Segel 1976, p. 227). The exponential rate of removal for each of the 16 amino acids was transformed by taking the natural log of the substrate concentration. The rate of uptake was determined by least-squares regression analysis of the ln-transformed data. The first-order depletion constant, $k$, was then calculated for each amino acid from the regression analysis as follows:

$$
\mathrm{k}=[(\ln [\mathrm{S}] \text { at } 0 \mathrm{~min})-(\ln [\mathrm{S}] \text { at } \mathrm{Y} \min )] / Y \min
$$

where $[\mathrm{S}]=$ the substrate concentration at the start of the experiment $(0 \mathrm{~min})$ and at a point ( $\mathrm{Y}$ min) calculated from the regression line of all the data. The rate of net uptake per larva-min can then be calculated as: $k$, times the amount of substrate $(\mathrm{mol})$ in the flask, divided by the total number of larvae in the flask. All calculations were based on a substrate concentration of $100 \mathrm{n} M$ for each amino acid.

The data so calculated are shown in histogram form in Fig. 3 to illustrate 2 points. First, the larvae can 


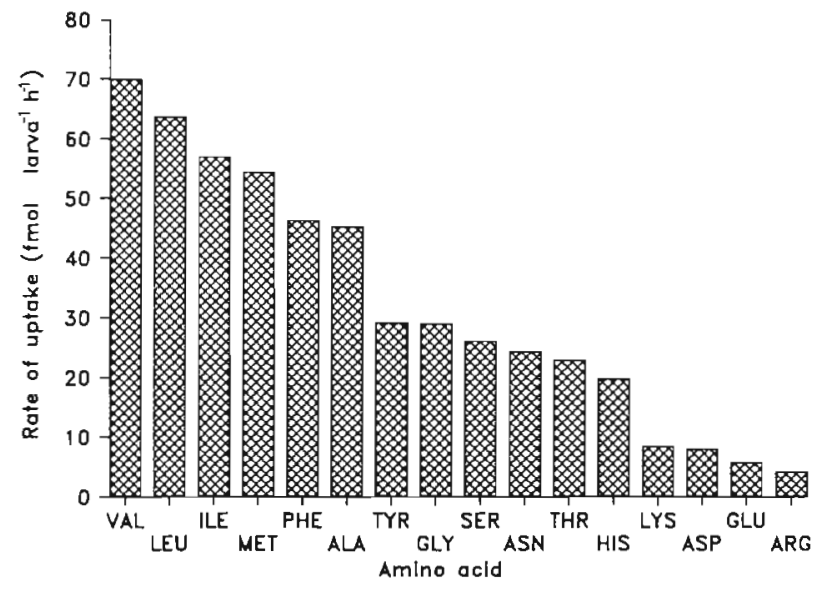

Fig. 3. Crassostrea gigas. Uptake rate for a mixture of 16 amino acids by axenic larvae. Rate for each substrate was calculated from the first-order depletion constant for that particular substrate, assuming a concentration of $100 \mathrm{n} M$ for each amino acid (see text). The $r^{2}$ values for the regression of the $\ln$-transformed rates ranged from a low of 0.92 (Glu) to a high of 0.99 (Phe)

transport all acidic, basic and neutral amino acids tested, and second, in a mixture of 16 amino acids each at equimolar concentrations, there is a much faster uptake rate for neutral, nonpolar amino acids (Val, Leu, Ile, Met, Phe) than for acid and basic amino acids (Arg, Asp، Lys, Glu).

\section{Comparison of influx and net flux rates}

Fig. 4 shows the net flux and influx rates of 4 substrates into Crassostrea gigas larvae, as measured by direct chemical analysis (HPLC) and radioisotope techniques, respectively. The data shown were obtained from different experiments at 4 different densities of larvae. The aim of these experiments was to compare flux rates for a given substrate. Hence, the 4 graphs should not be compared directly with respect to uptake rates for the different substrates. Taken together, the data illustrate that influx of a radiolabel is a reasonable measure of net flux. However, only for leucine is there a near-perfect match of both measurement techniques. Larvae held in seawater, to which no amino acids were added, showed no efflux of any amino acid other than taurine (see below).

\section{Transport kinetics of single substrates}

The kinetics of ${ }^{14} \mathrm{C}$-alanine and ${ }^{14} \mathrm{C}$-leucine transport were determined for sibling larvae. In Fig. 5 the data are combined to allow a direct comparison of the kinetic curves. Each data point represents the slope of the
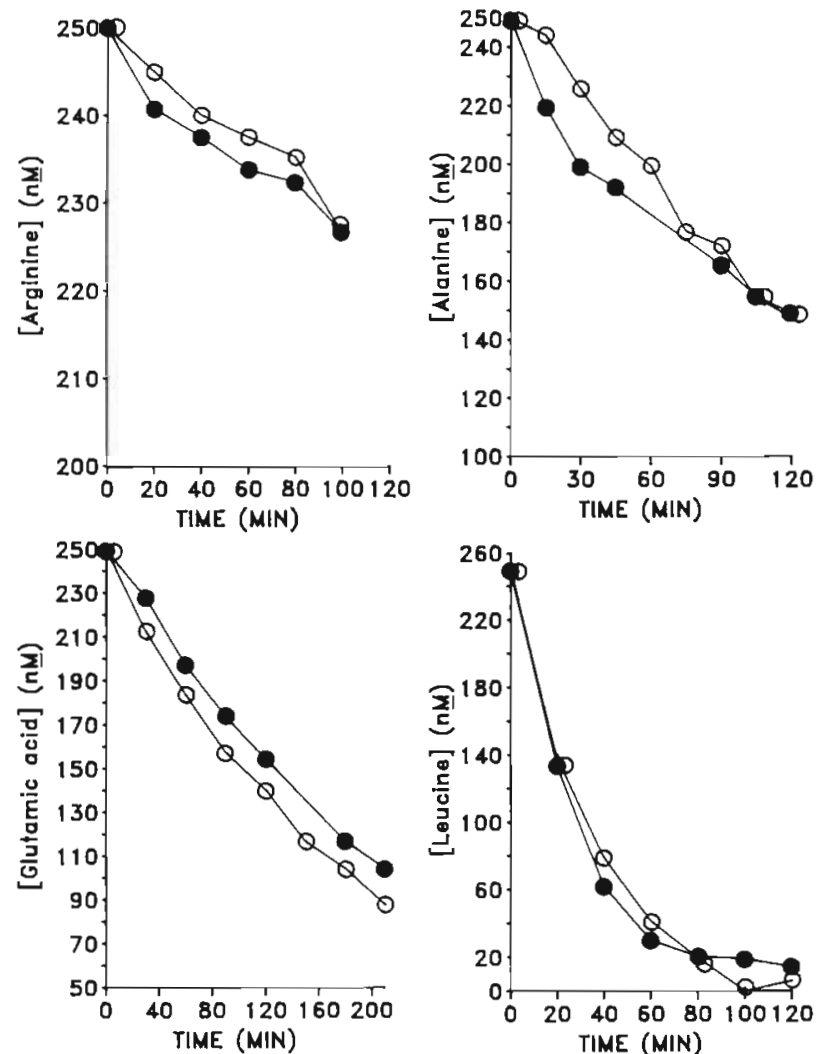

Fig. 4. Crassostrea gigas. Relation for axenic larvae between influx and net flux of arginine (2586 larvae $\mathrm{ml}^{-1}$ ), alanine (3200 larvae $\mathrm{ml}^{-1}$ ), glutamic acid (2500 larvae $\mathrm{ml}^{-1}$ ) and leucine (2586 larvae $\mathrm{ml}^{-1}$ ). (•) Concentrations determined by HPLC analysis; (o) concentrations determined by isotope techniques

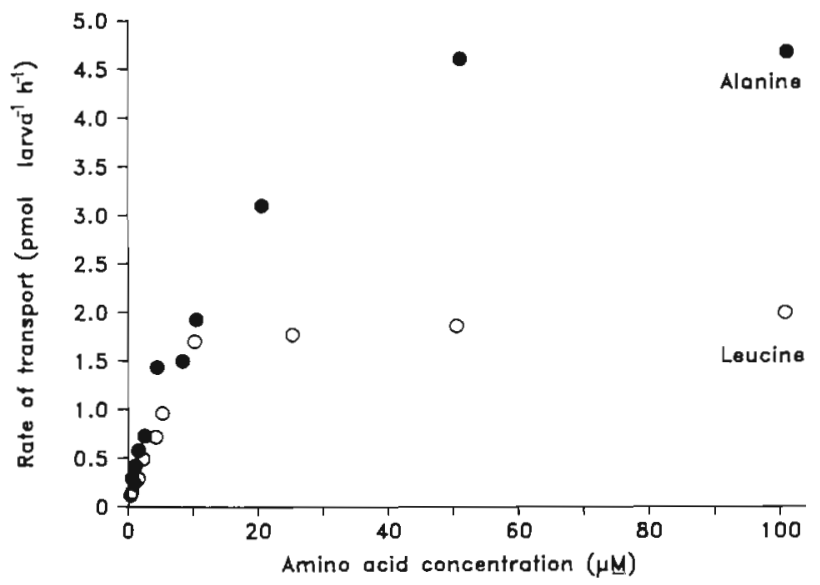

Fig. 5. Crassostrea gigas. Kinetics of transport for alanine and leucine by sibling larvae (volume of each time course experiment $=10 \mathrm{ml}, 492$ larvae $\mathrm{ml}^{-1}$ ). (•) Transport rates for alanine; (o) transport rates for leucine

time course experiment for that particular substrate concentration. The slopes of 20 such time course experiments were carried out to construct the kinetic curves given in Fig. 5. Eadie-Hofstee plots were used to 
Table 1. Crassostrea gigas. Kinetic values for the transport of alanine and leucine by axenic larvae. Eadie-Hofstee plots of the kinetic data given in Fig. 5 were used to determine the $\mathrm{K}_{\mathrm{t}}$ (slope) and $\mathrm{J}_{\max }$ ( $y$-intercept) for each substrate using sibling larvae

\begin{tabular}{|c|c|c|c|c|}
\hline Substrate & $\begin{array}{c}\mathrm{K}_{1} \text { (SE of slope) } \\
(\mu M)\end{array}$ & $\begin{array}{c}J_{\max } \text { (SE of } y \text {-intercept) } \\
\left(\mathrm{pmol} \text { larva } \mathrm{t}^{-1} \mathrm{~h}^{-1}\right)\end{array}$ & $r^{2}$ & $n$ \\
\hline Alanine & $11.4(1.5)$ & $4.6(1.2)$ & 0.87 & 10 \\
\hline Leucine & $7.1(0.9)$ & $2.2(0.6)$ & 0.86 & 10 \\
\hline \multicolumn{5}{|c|}{ ANOVA of compared regressions for $\mathrm{E}-\mathrm{H}$ plots used to calculate $\mathrm{K}_{\mathrm{t}}$ and $\mathrm{J}_{\mathrm{max}}$ for alanine and leucine: } \\
\hline Source & df & Variance ratio & $F(0.05)$ & \\
\hline Combined regression & 1 & 89.46 & 4.41 & \\
\hline Between slopes $\left(K_{t}\right)$ & 1 & 4.66 & & \\
\hline Between constants $\left(J_{\text {max }}\right)$ & 1. & 54.46 & & \\
\hline Residual & 18 & & & \\
\hline Total & 21 & & & \\
\hline
\end{tabular}

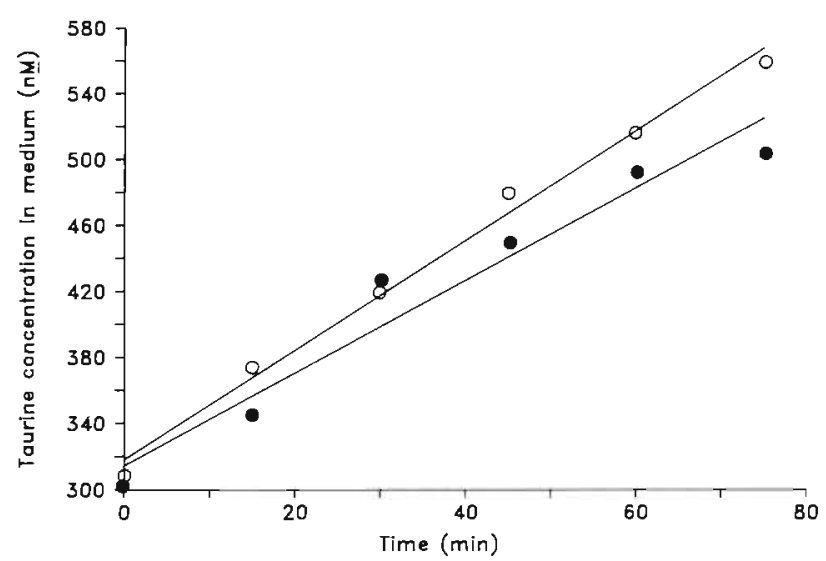

Fig. 6. Crassostrea gigas. Efflux of taurine from axenic larvae in the presence of $(\bullet) 16$ amino acids, each at $250 \mathrm{nM}$, and in natural seawater (o). Experiments were carried out with 3200 larvae $\mathrm{ml}^{-1}$ ANOVA of compared regressions for rates of taurine efflux from axenic $C$. gigas larvae into seawater in the presence and absence of a 16 amino acid mixture in the medium:

\begin{tabular}{lrrc}
\multicolumn{1}{c}{ Source } & df & \multicolumn{1}{c}{ VR } & $F(0.05)$ \\
\hline Combined regression & 1 & 296.01 & 5.32 \\
Between slopes & 1 & 2.12 & \\
Between constants & 1 & 6.33 & \\
Residual & 8 & & \\
Total & 11 & &
\end{tabular}

derive the kinetic constant $J_{\max }$, the maximum transport capacity, and $K_{t}$, the substrate concentration at half $\mathrm{J}_{\text {max }}$. $\mathrm{K}_{\mathrm{t}}$ for alanine was $11.4 \mu M$ and $\mathrm{J}_{\max }$ was 4.6 pmol larva ${ }^{-1} h^{-1}$ (Table 1 ). The corresponding $K_{\mathrm{t}}$ and $\mathrm{J}_{\max }$ values for leucine transport by Crassostrea gigas larvae were $7.1 \mu M$ and $2.2 \mathrm{pmol}_{\text {larva }}{ }^{-1} \mathrm{~h}^{-1}$, respectively. An analysis of variance of the compared regression (Table 1) for the Eadie-Hofstee plots for alanine and leucine showed that the values for $K_{t}$ for each substrate are only barely significantly different (var- iance ratio, $\mathrm{VR}=4.66 ; p<0.05, \mathrm{~F}=4.41)$, whereas the values for $\mathrm{J}_{\max }$ are very different (VR $=54.46$; $p<$ 0.001). Even though the application of ANOVA statistics to Eadie-Hofstee plots is not strictly correct, the data do illustrate that the affinities of both transport systems are similar and that the major difference in the transport rates of alanine and leucine is explained by the differences in maximum transport capacities.

\section{Net fluxes of taurine}

In all experiments a net efflux of taurine from axenic Crassostrea gigas larvae was observed. Taurine efflux was also observed from nonaxenic $C$. gigas larvae of several different sizes $(70,150,320 \mu \mathrm{m})$. This efflux occurred whether or not other amino acids were present in the medium. Fig. 6 shows the rate of appearance of taurine in the medium in the presence and absence of the mixture of 16 amino acids used previously (Fig. 1). By analysis of variance, the rates of efflux of taurine were not significantly different whether or not other amino acids were being transported from the medium (ANOVA in legend to Fig. 6).

In another experiment, using different larvae to those used in Fig. 6, simultaneous net fluxes of taurine were measured in order to determine whether Crassostrea gigias larvae have a transport system for taurine. The rate of appearance of ${ }^{14} \mathrm{C}$-taurine into axenic $C$. gigas larvae was determined (see techniques under Transport kinetics) in a time course experiment during which samples of the medium were also collected for HPLC analysis of taurine efflux. The rate of taurine efflux into the medium was $581 \mathrm{fmol}^{2} \mathrm{arva}^{-1} \mathrm{~h}^{-1}\left(r^{2}=0.98\right)$. The rate of ${ }^{14} \mathrm{C}$-taurine influx was $320 \mathrm{fmol} \mathrm{larva}{ }^{-1} \mathrm{~h}^{-1}\left(r^{2}=\right.$ 0.95) from a concentration of $0.89 \mu$ at the start of the experiment. 


\section{DISCUSSION}

Axenic larvae of the bivalve Crassostrea gigas are capable of net uptake of amino acids from nanomolar solutions in seawater. When presented with an equimolar mixture of acidic, basic and neutral amino acids, all amino acids showed net flux into the larvae (Fig. 1), with the exception of taurine. The ability of bivalve larvae to transport acidic, basic and neutral amino acids is similar to that observed for adult bivalves (Mytilus edulis; Manahan et al. 1983b), but different to that observed for axenic sea urchin larvae where only the uptake of neutral amino acids could be detected (Manahan et al. 1983a). Larvae of another mollusk, the gastropod Haliotis rufescens, have a similar pattern to that observed for C. gigas, strengthening the argument that both adult and larval mollusks have transport systems for a wider range of amino acid classes than those systems found in the echinoderms. However, similar studies carried out with larvae of another protostome, the echiuran worm Urechis caupo (Jaeckle \& Manahan 1989), revealed a pattern more like that described for echinoderm larvae than that found for bivalve (this study) and gastropod larvae (Jaeckle \& Manahan unpubl.). It appears that differences in transport ability of specific amino acid classes are not an inherent difference between the deuterostomes and the protostomes. The biological significance of these qualitative differences is not yet evident.

Measuring the simultaneous uptake of multiple substrates from mixtures provides useful qualitative data on uptake rates. However, data obtained in this way may not be useful in determining the quantitative relationship between transport rates for different substrates. A comparison of Figs. 3 and 5 illustrates this point. In a mixture of 16 amino acids, the larvae of Crassostrea gigas preferentially took up leucine at a rate of $64 \mathrm{fmol} \mathrm{larva}{ }^{-1} \mathrm{~h}^{-1}\left(r^{2}=0.99\right)$. In comparison alanine was removed at a rate of $45 \mathrm{fmol}$ larva $^{-1} \mathrm{~h}^{-1}$ $\left(r^{2}=0.95\right)$. The reverse is seen, however, when the kinetics of transport for these 2 substrates are studied independently (Fig. 5). At any substrate concentrations above the $K_{t}$, the rate of uptake of alanine is higher than that determined for leucine. Although the $K_{t}$ values for both substrates are similar (alanine $=11 \mu \mathrm{M}$; leucine $=7, \mu M$ ), the values for $\mathrm{J}_{\max }$ differ by a factor of more than 2 for alanine and leucine (Table 1), at 4.6 and 2.2 pmol larva $^{-1} \mathrm{~h}^{-1}$, respectively. It is important to mimic the concentrations and mixtures of individual amino acids which occur in the natural environment of the organism in question in order to determine ecologically realistic uptake rates. O'Dell \& Stephens (1986) were able to accomplish this by measuring the amino acid concentrations in the environment of the worm Pareurythoe california, a species found near sediments.
However, given the poor state of our present knowledge about larval distributions in the sea (Young \& Chia 1987), the possible amino acids concentrations that a bivalve larva might encounter in its microhabitat can only be speculated upon.

The relation shown in Fig. 4 demonstrates that there is a reasonably close fit between the influx and net flux of acidic, basic and neutral amino acids in axenic Crassostrea gigas larvae. However, there is a net efflux of taurine from the larvae, even though the larvae do possess a transport system for taurine. In larvae, the transport system for taurine seems to be incapable of recycling amino acids lost across the epithelium as has been suggested for taurine fluxes in adult bivalves (Wright \& Secomb 1986). Taurine is the major component of the free amino acid pools of many marine invertebrates (Allen \& Garrett 1971) and comprises approximately $70 \%$ of the total pool in axenic $C$. gigas larvae (unpubl. obs.). A net efflux of taurine has also been observed for gastropod larvae Haliotis rufescens where, again, taurine is the major constituent of the free amino acid pools (Jaeckle \& Manahan unpubl.). The observed efflux of taurine is not an artifact of the experimental procedures; similar flux experiments on developing eggs of the sea urchin Strongylocentrotus purpuratus (unpubl. obs.) and larvae of the echiuran worm Urechis caupo (Jaeckle \& Manahan 1989) showed no efflux of the major constituent of the free amino acid pools, which is glycine in both species. Taurine loss from $C$. gigas larvae is probably passive and appears not to be coupled to the uptake of other amino acids (Fig. 6). This suggests that larvae must have a continuous requirement for taurine. Whether C. gigas larvae meet this requirement by biosynthesis or by dietary input will be considered in another study.

The metabolic rate for $70 \mu \mathrm{m}$ D-veligers of Crassostrea gigas has been measured by Gerdes (1983). Using his allometric equation, and correcting for the difference in temperature, larvae used for the amino acid uptake experiments reported here would have a metabolic rate of about $200 \mathrm{pl} \mathrm{O}_{2}$ larva $^{-1} \mathrm{~h}^{-1}$. In order for the uptake of alanine to account for $100 \%$ of the oxidative needs of $70 \mu \mathrm{m} \mathrm{C}$. gigas, the substrate concentration of alanine would have to be close to the $K_{t}$ value for alanine. At a concentration of $10 \mu \mathrm{M}$ alanine, the rate of uptake would be $195 \mathrm{pg} \operatorname{larva}^{-1} \mathrm{~h}^{-1}$, the complete oxidation of which could account for an oxygen consumption of $195 \mathrm{pl} \mathrm{larva}^{-1} \mathrm{~h}^{-1}(1 \mathrm{pg}$ amino acid $=1 \mathrm{pl} \mathrm{O}$; Stephens 1963).

Interestingly, if the substrate concentration is at $K_{t}$, then Crassostrea gigas larvae could account for their energetic nedds by uptake of dissolved amino acids. $\mathrm{K}_{\mathbf{t}}$ is usually taken to be a measure of the substrate concentration for which an transport system is adapted (Stephens 1988). However, a concentration of $10 \mu M$ is 
much too high and environmentally unrealistic for measurements of bulk seawater samples taken from the water column (Carlucci et al. 1984, Henrichs \& Williams 1985). Seawater near and in the sediments would contain such concentrations (Clark et al. 1972, Henrichs \& Farrington 1979). The percent of time that C. gigas larvae spend near the sediment, as opposed to swimming in the water column, is unknown. C. gigas is an estuarine species, and the swimming larval stages of Crassostrea spp. have been reported to spend time near the sediment during low tides to prevent themselves from being removed from the estuarine environment (Wood \& Hargis 1971). Depending on the substrate concentration, the uptake of dissolved amino acids, and presumably other components of the total pool of DOM, can make a substantial contribution to the energetics of this species.

Acknowledgements. I am grateful to S. D. Nourizadeh for his assistance during the course of some of these experiments. Special thanks to Lee Hansen for his interest and for supplying ripe adults. This work was supported by NOAA Office of Sea Grant (U.S.C. grant \# R/RD-27) and, in part, by a grant from the National Science Foundation (OCE-86-0889).

\section{LITERATURE CITED}

Allen, J. A., Garrett, M. R. (1971). Taurine in marine invertebrates. Adv. Mar. Biol. 9: 205-253

Bass, N., Chapman, G., Chapman, J. H. (1969). Uptake of leucine by larvae and adults of Nereis. Nature, Lond. 211: 476-477

Carlucci, A. F., Craven, D. B., Henrichs, S. M. (1984). Diel production and microheterotrophic utilization of dissolved free amino acids in waters off southern California. Appl. environ. Microbiol. 48: 165-170

Clark, M. E., Jackson, G. A., North, W. J. (1972). Dissolved free amino acids in southern California coastal waters. Limnol. Oceanogr. 17: 749-758

D'Agostino, A. (1972). Antibiotics in cultures of invertebrates. In: Smith, W. L., Chanley, M. H. (eds.) Culture of marine invertebrate animals. Plenum, New York, p. 109-133

Davis, J. P., Stephens, G. C. (1984). Uptake of free amino acids by bacteria-free larvae of the sand dollar Dendraster excentricus. Am. J. Physiol. 247: R733-R739

Gerdes, D. (1983). The Pacific oyster Crassostrea gigas. Part II. Oxygen consumption of larvae and adults. Aquaculture 31. $221-231$

Ferguson, J. C. (1982). A comparative study of the net metabolic benefits derived from the uptake and release of free amino acids by marine invertebrates. Biol. Bull. mar. biol. Lab., Woods Hole 162: 1-17

Henrichs, S. M., Farrington, J. W. (1979). Amino acids in interstitial waters of marine sediments. Nature, Lond. 297 955-959

Henrichs, S. M., Williams, P. M. (1985). Dissolved and particulate amino acids and carbohydrates in the sea surface microlayer. Mar. Chem. 17 141-164

Jaeckle, W. B., Manahan, D. T. (1989). Amino acid uptake and metabolism by larvae of Urechis caupo (Echiura), a new species in axenic culture. Biol. Bull. mar. biol. Lab., Woods Hole 176 (3): in press
Johannes, R. E., Coward, S. J., Webb, K. K. (1969). Are dissolved amino acids an energy source for marine invertebrates? Comp. Biochem. Physiol. 29: 283-288

Jones, B. N., Paabo, S., Stein, S. (1981). Amino acid analysis and enzymatic sequence determination of peptides by an improved o-phthaldialdehyde precolumn labeling procedure. J. Liquid Chromatogr. 4: 565-586

Jørgensen, C. B. (1976). August Putter, August Krogh, and modern ideas on the use of dissolved organic matter in aquatic environments. Biol. Rev. 51 291-328

Krogh, A. (1931). Dissolved substances as food of aquatic organisms. Biol. Rev, 6: 412-442

Langdon, C. J. (1983). Growth studies with bacteria-free oyster (Crassostrea gigas) larvae fed on semi-defined artificial diets. Biol. Bull. mar. biol. Lab., Woods Hole 164: 227-235

Lindroth, P., Mopper, K. (1979). High performance liquid chromatographic determination of subpicomole amounts of amino acids by precolumn derivatization with o-phthaldialdehyde. Analyt. Chem. 51: 1667-1674

Manahan, D. T. (1983). The uptake and metabolism of dissolved amino acids by bivalve larvae. Biol. Bull. mar. biol. Lab., Woods Hole 164: 236-250

Manahan, D. T., Crisp, D. J. (1983). Autoradiographic studies on the uptake of dissolved amino acids by bivalve larvae. J. mar. biol. Ass. U.K. 63: 673-682

Manahan, D. T., Davis, J. P., Stephens, G. C. (1983a). Bacteriafree sea urchin larvae: selective uptake of neutral amino acids from seawater. Science 220: 204-206

Manahan, D. T., Wright, S. H., Stephens, G. C. (1983b). Simultaneous determination of net uptake of 16 amino acids by a marine bivalve. Am. J. Physiol, 244: R832-R838

Manahan, D. T., Wright, S. H., Stephens, G. C., Rice, M. A. (1982). Transport of dissolved amino acids by the mussel Mytilus edulis: demonstration of net uptake from natural seawater. Science 215: 1253-1255

O'Dell, S. J., Stephens, G. C. (1986). Uptake of amino acids by Pareurythoe california: substrate interaction modified net flux from the environment. Biol. Bull. mar. biol. Lab., Woods Hole 171: 682-693

Pequignat, E. (1973). A kinetic and autoradiographic study of the direct assimilation of amino acids and glucose by organs of the mussel Mytilus edulis. Mar. Biol. 19: 227-244

Porter, K. G., Feig, Y. S. (1980). The use of DAPI for identifying and counting aquatic microflora. Limnol. Oceanogr 25: 943-948

Pütter, A. (1909). Die Emährung der Wassertiere und der Stoffhaushalt der Gewässer. Verlag Gustav Fischer, Jena

Reish, D. J., Stephens, G. C. (1969). Uptake of organic material by aquatic invertebrates. $V$ The influence of age on the uptake of glycine- $\mathrm{C}^{14}$ by the polychaete Neanthes arenaceodentata. Mar Biol. 3: 352-355

Rice, M. A., Wallis, K., Stephens, G. C. (1980). Influx and net flux of amino acids into larval and juvenile european flat oysters, Ostrea edulis (L.). J. exp. mar. Biol. Ecol. 48: 51-59

Ruby, E. G., Greenberg, E. P., Hastings, J. W. (1980). Planktonic marine luminous bacteria: species distribution in the water column. Appl. environ. Microbiol. 39: 302-306

Segel, I. H. (1976). Biochemical calculations, 2nd edn. John Wiley, New York

Siebers, D. (1979). Transintegumentary uptake of dissolved amino acids in the sea star Asterias rubens. A reassessment of its nutritional role with special reference to the significance of heterotrophic bacteria. Mar. Ecol. Prog. Ser 1: $169-177$

Sieburth, J. M. (1975). Microbial seascapes. University Park Press, Baltimore

Southward, A. J., Southward, E. C. (1972). Observations on 
the role of dissolved organic compounds in the nutrition of benthic invertebrates. II. Uptake by other animals living in the same habitat as pogonophores, and by some littoral polychaeta. Sarsia 48: 61-68

Stephens, G. C. (1963). Uptake of organic material by aquatic invertebrates. II. Accumulation of amino acids by the bamboo worm, Clymenella torquata. Comp. Biochem. Physiol. 10: $191-202$

Stephens, G. C. (1988). Epidermal amino acid transport by marine invertebrates. Biochim. Biophys. Acta. 947: $113-138$

Stephens, G. C., Schinske, R. A. (1961). Uptake of amino acids by marine invertebrates. Limnol. Oceanogr 6: 175-181

Thomson, C. W. (1873). The depths of the sea. Macmillian, London

Wood, L., Hargis, W J. (1971). Factors associated with the

This article was presented by Professor N. D. Holland, La Jolla, California, USA transport and retention of bivalve larvae in a tidal estuary. In: Crisp, D. J. (ed.) Proc. 4th European Marine Biology Symposium. Cambridge Univ. Press, London, p. 29-44

Wright, S. H. Secomb. I W (1986). Epithelial amino acid transport in marine mussels: role in net exchange of taurine between gills and seawater J. exp. Biol. 121: $251-270$

Wright, S. H., Stephens, G. C. (1978). Removal of amino acid during a single pass across the gill of marine mussels. J. exp. Zool. 205: 337-352

Young, C. M., Chia, F. S. (1987). Abundance and distribution of pelagic larvae as influenced by predation, behavior and hydrographic factors. In: Giese, A. C., Pearse, J. S., Pearse, V. B. (eds.) Reproduction of marine invertebrates, Vol. 9. Blackwell-Boxwood Press, Palo Alto, California, p. $385-463$

Manuscript first received: August 5, 1988

Revised version accepted: January 20, 1989 